\title{
Modelling the Trend of Road Traffic Accidents in Accra
}

\author{
Edwin Mends-Brew*, Joseph Dadzie, Ben Apau Dadson, Martin Owusu Amoamah
}

Department of Mathematics \& Statistics, Accra Technical University, Accra, Ghana

\section{Email address:}

emendsbrew@yahoo.com (E. Mends-Brew), kobenagyesi@yahoo.com (J. Dadzie), apaudadson@yahoo.co.uk (B. A. Dadson), martin_amoamah@yahoo.com (M. O. Amoamah)

${ }^{*}$ Corresponding author

\section{To cite this article:}

Edwin Mends-Brew, Joseph Dadzie, Ben Apau Dadson, Martin Owusu Amoamah. Modelling the Trend of Road Traffic Accidents in Accra. Mathematical Modelling and Applications. Vol. 3, No. 1, 2018, pp. 1-8. doi: 10.11648/j.mma.20180301.11

Received: October 26, 2017; Accepted: November 22, 2017; Published: January 2, 2018

\begin{abstract}
Road transportation remains the dominant mode of transporting goods and commuters in Ghana. Over the last couple of decades, the Government of Ghana has aggressively pursued a comprehensive road infrastructural development and maintenance programmes with the aim of improving the entire road network in response to increase in travel and transportation. This is as a result of growth and expansion of economic activity with raised consumption levels of the people. Consequently, this improvement is aimed at reducing the menace and the carnage on roads in the country. Unfortunately, with the increasing road network, the number of fatalities has also been on the rise leading to great concerns for road safety. The purpose of this paper is to come out with a predictive mathematical model on the trend of Road Traffic Accident (RTA) occurrence in Ghana. Descriptive data in the public domain from statutory bodies especially the Motor Traffic and Transport Directorate (MTTD) of the Ghana Police Service on RTAs together with a host of academic papers on the subject matter were used as sources of information. The result of the sixth order polynomial analysis showed an r-squared value of 0.957 which was statistically significant inferring that the model has a $95.7 \%$ accuracy of predicting road traffic accidents in Ghana. It was also evident that road traffic accidents significantly increased with increased stretch of roads $(\mathrm{km})$, absence of road safety officials and the blatant disregard for road safety measures aimed at ensuring safety on the roads. Based on the findings, recommendations were advised on how to reduce the phenomenon of traffic accidents in Ghana particularly in the Greater Accra region.
\end{abstract}

Keywords: Road Traffic Accidents (RTA), Predictive Model, Sixth-Order Polynomial, Road Safety

\section{Introduction}

Road transportation is the major system of transportation in Ghana, which relies on various kinds of vehicles as means of transport [29]. According to the Ministry of Transport Report [23], most people in the country rely mainly on road transport for their daily commuting, as well as the conveyance of raw materials and food commodities. Statistics show that about $96 \%$ of the country's freight use road transportation [29]. However, despite increased road safety campaigns due to its huge demand, the rate at which accidents occur on our roads is very alarming. It is an acknowledged fact that one of the major challenges, this country is still battling with is Road Traffic Accidents (RTAs). A renowned pathologist and former Head of the Ghana Health Service (Professor Agyeman Badu Akorsah ) rightly hammered home this fact when he stated that "the most 'deadly disease' in Ghana at the moment is motor accidents"[26]. Indeed this conquerable foe is voraciously gobbling human and economic resources [26]. According to statistical report by [29], Ghana loses a colossal sum of GH $\varnothing 165,000$ representing $1.6 \%$ of its GDP, yearly in resolving incidence of road traffic accidents such as medical expenses of victims, damage to vehicles and insurance cost among others. In conservative terms, the country loses about $2 \%$ of its GDP annually to road accidents. The alarming increase in morbidity and mortality due to RTAs over the past few decades is a matter of great concern globally [2]. Available Statistics reveal that, every individual stands the risk of this threat because annually, an estimated number of 1.2 million people die globally, due to road traffic accidents with more than 2500 deaths daily [12]. The World Health 
Organization, (WHO), a specialized agency of the United Nations, in its Global Status Report on Road Safety [43], stated that over $90 \%$ of the world's fatalities on the road occur in low-income and middle-income countries, which have only $48 \%$ of the world's registered vehicle population. Nonetheless, these countries are shouldering a rather disproportionate share of the spoils. RTAs are a global public health problem. Currently ranked ninth, RTAs are projected to upsurge to become the fifth leading cause of death by 2030. It is worth mentioning that, of the worldwide estimated number of road deaths occurring annually, $74 \%$ are in developing countries [37].

Incidentally, using British and American crash reports as data, [33] found that $57 \%$ of crashes were due solely to driver factors, $27 \%$ to combined roadway and driver factors, $6 \%$ to combined vehicle and driver factors, $3 \%$ solely to roadway factors, $3 \%$ to combined roadway, driver, and vehicle factors, $2 \%$ solely to vehicle factors and $1 \%$ to combined roadway and vehicle factors. These findings were further corroborated according to the Motor Traffic and Transport Directorate (MTTD) of the Ghana Police Service report in 2005, which indicated that, driver error, mechanical failure and pedestrian action are the major causes of road traffic accidents.

Repeatedly, media reports reveal that Ghana's road traffic accidents prevalence is unusually high among developing countries. In 2001, for instance, Ghana was rated as the second highest road traffic accident-prone nation among six West African countries, with 73 deaths per 1000 accidents. Road traffic accidents surged upwards in 2001 to 11,291 with 1660 fatalities, while decreasing slightly in 2002 to 10,718 but with 1665 fatalities. Though road traffic accidents further declined to 10,644 in 2003 , fatalities piercingly rose to 11,718. According to officials of the MTTD of the Police Service, during this period, there were 78 fatalities, 373 of which were serious injury cases and 966 minor incidents among others. Expectedly, the number of road traffic accidents in the country sharply rose up to 12,164 in 2004 but decreased suddenly to 11,305 in 2005 . Ghana records about 10,000 fatal road traffic accidents every year, out of which 1,600 people perished while 15,000 , are seriously injured, robbing the nation of precious lives. Thus, denying them the opportunity to meaningfully contribute to the nation's development.

Accra alone recorded, from January to March 2003, 1,417 motor accidents involving 2,125 vehicles. According to [46], The Greater Accra Region had recorded a total of 1,996 road traffic accidents cases from January to September, 2013 as against 1,807 recorded within the same period in 2012. This figure was the highest among the regional records and needed strategic efforts and teamwork from all stakeholders to reduce the trend. Currently, the region accounts for about 55 per cent of the national total of 3,719 road traffic accident cases recorded by the Ghana Police Service over the period under review. This state of affairs requires concerted efforts and shared responsibility from all stakeholders to help limit the rate and curtail their devastating impact on individuals, families, livelihoods and national development [46]. In his narrative, [46] maintains that the Greater Accra Region currently tops the list of national fatalities from road traffic accidents, having already recorded high cases of deaths within the third quarter of the year with accidents involving a total of 3,099 vehicles, which included commercial and private vehicles as well as motor cycles. The high incidence of these RTAs cases over the period under review were recorded by the Madina, Odorkor, Airport, Tesano and the Kaneshie divisions of the Ghana Police service as well as the Accra Regional MTTD with a regional total of 286 pedestrians knocked down, resulting in 76 fatalities, 402 serious injuries and 1,019 minor injuries [46].

Absurdly, the huge incidence of fatalities that were recorded in these accidents was regrettably preventable. However, the lack of responsiveness of a section of the road user population, particularly drivers has continued to exacerbate the prevalence of RTAs [46]. Moreover, in order to bring to the fore, the fatality and losses triggered by these RTAs, there is the urgent need to fashion out a predictive model on the trend of RTAs in the future if this menace is to be efficiently managed. Various researchers have used several models and techniques in predicting road traffic accidents but the most important requirement is for these models to have the minimal residual between the actual and predicted values.

The remainder of the paper is organized as follows; the ensuing section presents a brief overview of the incidence of RTAs. This is followed by a review of empirical literature pertaining to the study. Section 3 essentially deals with discussion of the methodology employed in conducting the research. Subsequently, results are presented and finally discussed in section 4 . The paper ultimately ends with drawn conclusions and recommendations in section 5 .

\section{The Prevalence of RTAs}

The spate of RTAs affect populations all over the world with varied contributing factors influencing the causes of RTAs in different regions of the world. Road Traffic Accidents are one of the leading causes of death in developing countries, particularly in Ghana. According to [14], it is believed that globally 1.4 million people are killed in RTAs and an estimated 20 million to 50 million people are injured or disabled from the effect of RTAs. It is anticipated that by the year 2020, RTAs will rank third of all causes of morbidity and mortality globally if the menace is left unchecked [40].

The WHO, in its 2010 report maintained that, Low and middle -income countries, even though have the lowest rate of vehicular penetration in the world, nevertheless $90 \%$ of victims of road traffic accidents occur in these countries. Particularly worrying, is the fact that, though RTA related fatalities seem to increase with Gross Domestic Product (GDP) per capita in lower income countries (including Ghana), it however decreases with GDP per capita in the wealthy countries of the north [10].

Globally the economic impact of RTAs is relatively huge 
according to [30], in his narrative on traffic injury prevention. It is estimated that US $\$ 518$ billion is spent globally on RTAs', with a whooping US \$65 billion being spent in low and middle income countries alone. Ironically, this amount is far in excess of what these countries receive annually in development aid [30]. It is worth mentioning that, increasingly RTAs tend to affect the most productive segment of the population as it happens to be the leading cause of death for the age cohort of between 15 - 30 years [42]. In addition to being a major health hazard leading to significantly high rates of fatality and disability, RTAs have a huge socio-economic impact on the victims and their respective families.

The global impact of RTAs on public health, prompted the World Health Organization to focus its attention in 2004 on a comprehensive universal campaign to curb this growing public health burden [44].

Despondently, with a worldwide estimate of less than 50 countries having strict and comprehensive laws relating to the key risk factors for road traffic accidents; such as drunk driving, over-speeding, non-usage of seat-belts and motorcycle helmets, it is predicted that by the year 2020 RTAs will lead to the deaths of 10 million people annually [42]. Additionally, this report also acknowledged that, $46 \%$ of vulnerable road users: cyclists, pedestrians and motorcyclists, are dying on the roads worldwide. World Health Organization report (2010) further indicated that, due to lack of the availability of road safety measures in developing countries, road traffic accidents rose by $70 \%$. This figure was further exacerbated by the inadequate attention to road safety and infrastructure.

\subsection{Major Causes of RTAs}

The major causes of RTAs among a plethora of others,

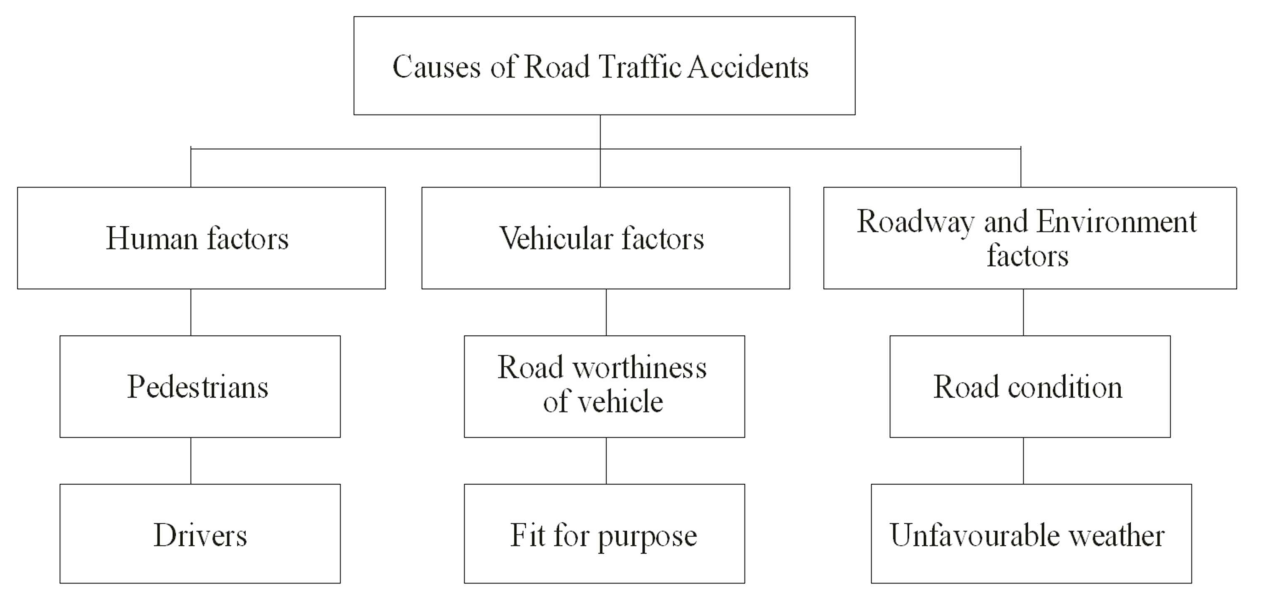

Figure 1. Causes of Road Traffic Accidents.

\subsection{Human Factors}

Since the advent of the automobile, human factors have remained the leading cause of traffic violations and increasingly become a routine source of danger for road users, particularly, passengers, pedestrians and sometimes the drivers themselves. In view of the fact that technology affords manufacturers the opportunity to produce safer cars include driver or human errors, road worthiness of the vehicle (s) involved, traffic infrastructures including engineering design, road maintenance and road traffic regulations [11]. Driver attitude including road rage and conduct, civility and behavior on the road, driving under the influence of alcohol and other narcotic substances, noncompliance with the use of seat belts, the domineering male driver, demography of the driver-population (over excited young adult and poorly coordinated drivers) [35] etc. are among the readily recognized human factors unleashing their carnage on our roads. These assertions were evidently supported by a recent study extensively conducted by [3], which essentially confirmed that risky driving in general and aggressive violation of traffic regulations in particular are major risk factors.

Generally, the occurrence of RTAs can be ascribed to various contributing factors and be broadly categorized into driver related, vehicle related and road related as shown in Figure 1 [4]. The road related factor could further be decomposed into roadway and environmental factors limited to unfavorable weather and road conditions. Moreover, poor maintenance of vehicles and the unregulated use of vehicles for unintended purposes are largely classified under vehicular factors. These factors, as well as their interactions, vary in the strengths of their contribution to RTAs. It is sufficient to mention that, the strongest and the pivotal factor in RTAs is primarily the driver (the human element). This is followed by the environment and the human - road environment interaction [31]. Thus, knowledge of driver behaviour, attention to the road and the vehicle is important in the reduction of the global scourge of Road Traffic Accidents especially in developing countries 
who are particularly prone to high speed (over-speeding), lack of attention, improper stopping, improper turning, violation of traffic laws, ignoring priority of way, using mobile phones whilst driving etc. have a significant role in many accidents and therefore knowledge of their characteristics is important in the analysis of traffic accidents. This assertion is expansively supported by extensive studies conducted by [16]; [19]; [36] and [5] who also acknowledged that RTAs are the leading cause of death among the adolescent and the young adult population of drivers. Since the human element contributes to $90 \%$ of all RTAs, it suffices to conclude that revoking the driver's licenses of accident prone drivers would be an adequate measure to improve road safety [31]. This measure would be in line with an approach known as the person approach [32] or the accident prone individual approach [18]. Both methodologies, however, are controversial and rarely lead to an improvement in road safety. Evidently, there is statistical proof that excluding accident prone drivers from road traffic scarcely yield the desired outcome [17]; [18]

\subsection{Road Traffic Accidents Injuries}

The World Health Organization has repeatedly, warned of the high proportion of road traffic accidents in developing countries if necessary measures are not instituted as a matter of policy, to reduce this menace. Traffic accidents and injuries have had negative impact on communities [22]. Nearly 3,000 people die daily on the roads worldwide and over a million others are disabled or injured every year. Cyclist, pedestrians; particularly children and the elderly are among the most vulnerable of road users [42]. Road traffic accidents are the most recurrent causes of injury-related deaths worldwide [8]. According to WHO reports [41] on road accidents, RTAs were classified as the 10th leading cause of death globally in 2008 . However, in middle- income countries, RTAs are rated as the 7th leading cause of death and injuries and expected to increase rapidly. Additionally, RTAs are projected to be the third most significant contributor to the global burden of disease by the year 2020 [41]. Across the globe, there are varied incidence of road traffic accident injuries ranging from pedal and motorcyclists to other forms of RTA related injuries. In a meta-regression analysis of seventeen studies, passengers ranked first amongst the non-fatal casualties reported. Expectedly, pedestrians were second, with the exception of one hospital based study by [15] in Addis Ababa that reported a very high proportion of pedestrians accounting for $91 \%$ of all traffic casualties.

In an extensively conducted study, by [9]; [27], driver injuries were the most chronicled in Saudi Arabia whilst motorcyclists recorded the most involved in Taiwan [45]. A relatively high proportion of cyclist injuries in South East Asian countries, ranging from 39 to $63 \%$, reflect the effects of traffic mix on the roads in the region [4]. In Africa's most populous country, Nigeria, RTAs over the last three decades have been particularly disturbing. According to [4], in 1976, there were 53,897 road traffic accidents resulting in 7,717 deaths. Although in 1981, the figure dwindled to 5,114 accidents. Nonetheless, the fatality increased to 10,236 which meant that, there was an average of almost 100 accidents and 28 deaths for every single day of that particular year [28]. Unfortunately, the situation in subsequent years has not been any better. In Ghana the incidence is no different. The number of people killed in RTAs has been rising steadily from 2000 through to 2006 and the prevalence has remained consistently high. Available data showed a progressive increase in RTAs related total fatalities per year from 1578 in 2000 to 1856 in the year 2006. However, the year 2004 registered an outstandingly high fatality figure of 2185 , which was attributed mainly to election year electioneering activities. According to the NRSC report [25], RTA trend has continued to maintain a steady rise from the year 2007 to 2011 [4].

Comparatively, one stands a very high likelihood of being involved in vehicular accident in a developing country, particularly Nigeria than in the United Kingdom with the former having a very high proportion of reported incidence of fatalities to injuries [4]. Additionally, while Czech Republic has only one death in 175 accidents, France, one death in 175, South Africa, one death in 47 accidents, Nigeria has one death in 2.65 accidents [6]. According to the General Department of Traffic in Libya between the beginning of January and the end of November 2010, there was a total of 2375 people killed in traffic accidents. This gives the country an annual road traffic fatality rate of 40.8 deaths per 100,000 population which is still horrific as the third most dangerous place for driving after Eritrea (48.4) and Egypt (42.0). In contrast, the figure for the US is 12.3 , Italy 8.7 , France 6.9, Japan 3.9 and the UK 3.6 [21]. Thus, the risk of dying as a result of a road traffic injury is highest in the Africa region and relatively lowest in the wealthy G-8 countries of the north.

\section{Methodology}

The methodology employed in the study was based on secondary data obtained from a number of government agencies namely; The Ministry of Transport, MTTD of the Ghana Police Service, National Road Safety Commission (NRSC), Newspaper reports etc. The study sought to conduct a detailed analysis of accident trend in the Greater-Accra region of Ghana. This is reckoned as a slight departure from what had hitherto been the focus of other studies conducted on RTAs. Quantitative methods under descriptive research design were employed in this research. Road accident data between the years 2009 and 2016 in the Greater-Accra region and the nine other administrative regions, collected from the Accra Regional MTTD was reviewed. Several models such as Autoregressive (AR), Autoregressive Moving Average (ARMA), Autoregressive Integrated Moving Average (ARIMA), Exponential and Polynomial methods, specifically the sixth-order polynomial model were extensively employed in the data analysis stage of the study. Multicollinearity tests were also conducted to remove collinearity of independent variables from the data set. The study was based on $95 \%$ confidentiality. 


\section{Findings and Discussion}

Regional Comparative Analysis of Road Accidents in the Year 2009

Table 1. Motor Accident Returns-Full Year Ending 31st December 2009, Nationwide.

\begin{tabular}{|c|c|c|c|c|c|c|c|}
\hline Station & Total number of cases & Vehicles Involved & Fatal & Serious & Minor & Persons Killed & Persons Injured \\
\hline Accra & 5,100 & 7,736 & 170 & 1,180 & 3,750 & 180 & 2,079 \\
\hline Tema & 1,244 & 1,682 & 136 & 408 & 700 & 127 & 860 \\
\hline Eastern & 1,398 & 1,813 & 241 & 446 & 711 & 313 & 2,130 \\
\hline Central & 898 & 1,171 & 126 & 258 & 514 & 187 & 898 \\
\hline Western & 1,036 & 1,296 & 153 & 319 & 564 & 172 & 1,183 \\
\hline Ashanti & 1,731 & 2,333 & 194 & 576 & 961 & 218 & 1,677 \\
\hline Volta & 431 & 487 & 86 & 192 & 153 & 104 & 248 \\
\hline Northern & 144 & 206 & 39 & 34 & 71 & 73 & 121 \\
\hline U/East & 62 & 93 & 27 & 20 & 15 & 24 & 50 \\
\hline U/West & 48 & 66 & 27 & 7 & 14 & 35 & 46 \\
\hline B/Ahafo & 473 & 526 & 99 & 122 & 252 & 154 & 475 \\
\hline Total & 12,565 & 17,409 & 1,298 & 3,562 & 7,705 & 1,587 & 9,767 \\
\hline
\end{tabular}

Source: Accra Central Regional MTTU.

Generally, nearly 3,400 people die on the world's roads every single day and an estimated tens of millions of people are injured or permanently disabled every year. Children, pedestrians, cyclists and the elderly are among the most vulnerable of road users.

As indicated earlier in this study, Greater Accra Region has consistently recorded the highest incidence of road traffic accidents in Ghana. From Table 1 above, out of the 12,565 total number of road accident cases that occurred nationwide in the year 2009, Greater Accra Region alone, recorded 6,344 for the Accra and Tema metropolis, representing 50.5\% of the nationwide aggregated cases of road traffic accidents. Ashanti Region recoded the second highest incidence of road traffic accidents in the year 2009. Thus, making the region, the second highest road traffic accident prone region in the year 2009, having recorded 1,731 road accidents representing $13.8 \%$ of the nationwide aggregation of road traffic accidents. In all, Upper West Region recorded the lowest road traffic accident cases (i.e. 48 cases) in the year 2009.

In 2010, road traffic accident cases in Accra (excluding Tema) went up by $1.922 \%$ from 5,100 to 5,198 and involved 8,311 vehicles. Incidentally, this number reduced to 4,838 RTA cases involving approximately 7,523 automobiles in 2011. However, the figure went up in 2012 with 5,178 total number of cases involving 8,263 vehicles. It continued to surge upwards in 2013 with an aggregation of 5,410 cases involving 8,584 vehicles. With massive road safety campaigns following the demise of very high profile personalities, the number of reported cases significantly dwindled in 2014 with 5,041 cases involving 8,197 vehicles. The subsequent year (2015) recorded the exact same set of figures registered in 2014 i.e. 5,041 cases involving 8,197 vehicles. This was indicative of sustained road safety campaign momentum that had intensified a year earlier. Moreover, between 2010 and 2015, a total of 1,708 people were killed while a record of 14,982 persons, were injured through RTAs. Out of the 1,708 people that were killed through RTAs between 2010 and 2015, 1,304 representing $76.3 \%$ were males whereas $23.7 \%$ were females.

In order to forecast the trend of road accidents in Accra, several models such as the AR, ARMA, ARIMA, Exponential and Polynomial methods were used. However, the sixth order polynomial analysis, ultimately proved to be the most appropriate fitting model that best predicts RTAs as can be seen evidently in the ensuing diagram; Figure 1. However, due to the existence of multicollinearity among the $x 2, x 4$, and $x 5$ under the sixth-order polynomial model as seen in Table 6 , they were conveniently removed from the analysis. Essentially, the independent variable had a relatively high $r$-square value of 0.878 after removing the collinearity. The result further indicates, that this figure was statistically insignificant, which is ultimately, explained on the basis of the fact that the p-value was greater than 0.05 . Nevertheless, using the cubic polynomial model, the r-square value obtained subsequently, was 0.957 which is significantly indicative of the fact that, the cubic model is 95.7\% accurate in predicting RTAs in the Accra Metropolis. The cubic polynomial model as can be seen in Tables 7, 8 and 9 is thus statistically significant since the p-values of the coefficients were less than 0.05 .

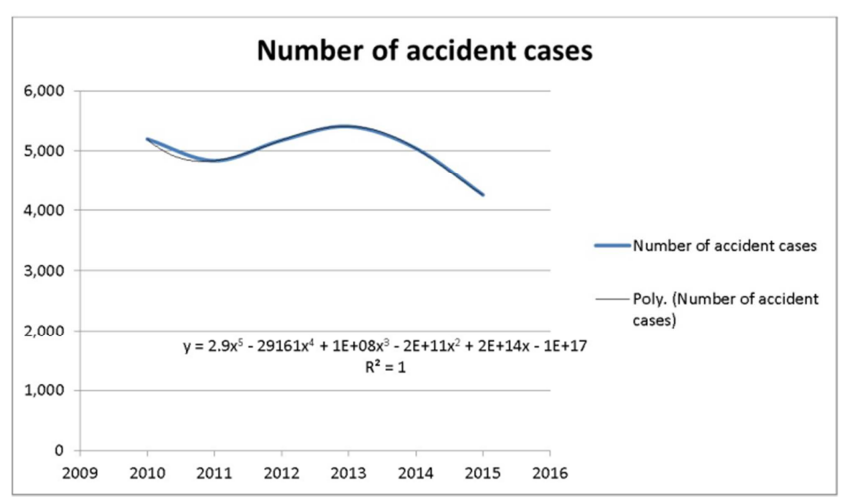

Figure 2. The Sixth-Order Polynomial Model. 
Table 2. Variables included and excluded

\begin{tabular}{llll}
\hline Variables Entered/Removed $^{\mathrm{a}}$ & & \\
\hline Model & Variables Entered & Variables Removed & Method \\
\hline 1 & $\mathrm{x} 6, \mathrm{x} 1, \mathrm{x} 3^{\mathrm{b}}$ & $\mathrm{x} 2, \mathrm{x} 4, \mathrm{x} 5$ & Enter \\
\hline
\end{tabular}

a. Dependent Variable: y.

b. Tolerance $=.000$ limits reached.
Table 3. Summary Model after the exclusion.

\begin{tabular}{lllll}
\hline \multicolumn{2}{l}{ Model Summary } & & & \\
\hline Model & R & R Square & $\begin{array}{l}\text { Adjusted R } \\
\text { Square }\end{array}$ & $\begin{array}{l}\text { Std. Error of } \\
\text { the Estimate }\end{array}$ \\
\hline 1 & $.937^{\text {a }}$ & .878 & .694 & 224.013 \\
\hline
\end{tabular}

a. Predictors: (Constant), x6, x1, x3.

Table 4. ANOVA Table after the exclusion.

\begin{tabular}{llllll}
\hline ANOVA $^{\mathbf{a}}$ & & & & \\
\hline Model & & Sum of Squares & df & Mean Square & F \\
\hline \multirow{3}{*}{1} & Regression & 719377.429 & 3 & 239792.476 & 4.778 \\
& Residual & 100363.905 & 2 & 50181.952 & \\
& Total & 819741.333 & 5 & & \\
\hline
\end{tabular}

a. Dependent Variable: y.

b. Predictors: (Constant), x6, x1, x3.

Table 5. Coefficients after the exclusion.

\begin{tabular}{|c|c|c|c|c|c|c|}
\hline \multicolumn{7}{|c|}{ Coefficients $^{\mathrm{a}}$} \\
\hline \multirow{2}{*}{\multicolumn{2}{|c|}{ Model }} & \multicolumn{2}{|c|}{ Unstandardized Coefficients } & \multirow{2}{*}{$\begin{array}{l}\text { Standardized Coefficients } \\
\text { Beta }\end{array}$} & \multirow{2}{*}{$\mathbf{t}$} & \multirow{2}{*}{ Sig. } \\
\hline & & B & Std. Error & & & \\
\hline \multirow{4}{*}{1} & (Constant) & 5229.929 & 455.993 & & 11.469 & .008 \\
\hline & $\mathrm{x} 1$ & -142.039 & 293.796 & -.656 & -.483 & .677 \\
\hline & $\mathrm{x} 3$ & 13.423 & 13.924 & 2.764 & .964 & .437 \\
\hline & $x 6$ & -.065 & .039 & -2.966 & -1.687 & .234 \\
\hline
\end{tabular}

a. Dependent Variable: y.

Table 6. Multicollinearity Statistics.

\begin{tabular}{|c|c|c|c|c|c|c|}
\hline \multicolumn{7}{|c|}{ Excluded Variables $^{a}$} \\
\hline \multirow{2}{*}{ Model } & & \multirow{2}{*}{ Beta In } & \multirow{2}{*}{$\mathbf{t}$} & \multirow{2}{*}{ Sig. } & \multirow{2}{*}{ Partial Correlation } & Collinearity Statistics \\
\hline & & & & & & Tolerance \\
\hline \multirow{3}{*}{1} & $\mathrm{x} 2$ & $45.346^{\mathrm{b}}$ & 63.403 & .010 & 1.000 & 5.953E-005 \\
\hline & $\mathrm{x} 4$ & $-57.568^{b}$ & -9.525 & .067 & -.995 & 3.654E-005 \\
\hline & $\times 5$ & $-59.919^{b}$ & -6.231 & .101 & -.987 & 3.325E-005 \\
\hline
\end{tabular}

a. Dependent Variable: y.

b. Predictors in the Model: (Constant), x6, x1, x3.

Table 7. Summary model for the Cubic Polynomial under curve estimation.

\begin{tabular}{llll}
\hline Model Summary & & & \\
\hline $\mathbf{R}$ & R Square & Adjusted R Square & Std. Error of the Estimate \\
\hline .978 & .957 & .893 & 132.403 \\
\hline
\end{tabular}

The independent variable is $\mathrm{x} 1$.

Table 8. ANOVA table for the Cubic Polynomial under curve estimation.

\begin{tabular}{|c|c|c|c|c|c|}
\hline \multicolumn{6}{|l|}{ ANOVA } \\
\hline & Sum of Squares & df & Mean Square & $\mathbf{F}$ & Sig. \\
\hline Regression & 784680.190 & 3 & 261560.063 & 14.920 & .063 \\
\hline Residual & 35061.143 & 2 & 17530.571 & & \\
\hline Total & 819741.333 & 5 & & & \\
\hline
\end{tabular}

The independent variable is $\mathrm{x} 1$.

Table 9. Coefficients for the Cubic Polynomial under curve estimation.

\begin{tabular}{|c|c|c|c|c|c|}
\hline \multicolumn{6}{|l|}{ Coefficients } \\
\hline & \multicolumn{2}{|c|}{ Unstandardized Coefficients } & \multirow{2}{*}{$\begin{array}{l}\text { Standardized Coefficients } \\
\text { Beta }\end{array}$} & \multirow{2}{*}{$\mathbf{t}$} & \multirow{2}{*}{ Sig. } \\
\hline & B & Std. Error & & & \\
\hline $\mathrm{x} 1$ & -1567.897 & 543.937 & -7.244 & -2.882 & .102 \\
\hline $\mathrm{x} 1 * * 2$ & 599.690 & 174.057 & 19.813 & 3.445 & .075 \\
\hline $\mathrm{x} 1 * * 3$ & -65.556 & 16.448 & -13.499 & -3.986 & .058 \\
\hline (Constant) & 6198.000 & 477.386 & & 12.983 & .006 \\
\hline
\end{tabular}




\section{Conclusions and Recommendations}

In conclusion, the MTTD database, NRSC and other reports including newspapers provide comprehensive insights into the extent and the degree of fatalities of RTAs. It was evident from the study that over $90 \%$ of RTAs are caused by human behavior. The reports also indicated a need for strengthening the RTAs surveillance so that accurate and adequate data on the incidence of RTAs and the ensuing mortality and morbidity tolls could be collected. Undoubtedly, this would afford the two relevant agencies; namely the MTTD and NRSC a thorough basis for scheduling effective intervention strategies to improve road safety in the metropolis. The NRSC which was duly established by the Government to develop programmes to promote road safety in the country and to coordinate policies related to safety on the roads should as a matter of urgency prioritized and concentrate more of its resources on public education as evidently enshrined in its mandate.

Additionally, concerted effort is required to have a comprehensive understanding of the various aspects of RTAs. Moreover, the recommendations made for strengthening surveillance could serve as an initial step towards reducing mortality and morbidity ensuing from the incidence of RTAs in the long term.

\section{Recommendations}

The MTTD and the NRSC should have the shared responsibility of preventing RTAs by adopting the following measures with the latter being required to inform, educate and communicate with members of the community, with an insistence upon the preventive behaviour while driving in respect of visibility conditions, weather conditions, the state of the road, traffic conditions etc.

Since it has been evidently established that most RTAs are driver related, measures taken to address the problem with inadequate training of drivers must include; increasing the number of driving lessons in the driving school, where the focus should not only be on acquiring the skills of driving an automobile, but also those associated with the correct behaviour in traffic along with increasing the number of tests before obtaining the driving license.

In addition, penalties must be stiffened for the lack of attention while driving such as suspension of the driving license if found using the mobile phone without hands free device while driving.

The Police control of speed and drunk driving must be intensified on the highways to stem the high incidence of traffic fatalities and injuries. This must include tightening sanctions for violating speed limits. The effectiveness of safety belts and helmet in decreasing mortality and injury severity after motor vehicle crashes has been confirmed by many studies. Thus, the use of safety belts and helmets must be strictly enforced in the country by the MTTD.

The findings of this study further support the need for the National Road Safety Commission to be adequately resourced and staffed with trained professionals and be responsible for accident data surveillance and analysis in addition to their core mandate.

\section{References}

[1] Administration of Traffic and Authorizations, Tripoli, Libya (2009).

[2] Afukaar F. K., Antwi P, Ofosu-Amaah S. (2003). Pattern of road traffic injuries in Ghana: Implications for control. Inj Control Saf Promot 2003; 10: 69-76.

[3] Al-Reesi, H., Ganguly, S. S., Al-Adawi, S., Laflamme, L., Hasselberg, M., \& Al-Maniri, A. (2013). Economic Growth, Motorization, and Road Traffic Injuries in the Sultanate of Oman, 19852009. Traffic Injury Prevention, 14 (3), 322-328. doi: 10.1080/15389588.2012.694088.

[4] Atubi, A. O. (2012) Determinants of Road Traffic Accident Occurrences in Lagos State: Some Lessons for Nigeria, International Journal of Humanities and Social Science Vol. 2 No. 6 [Special Issue - March 2012] 252.

[5] Atubi, A. O. and Onokala, P. C. (2009) Contemporary Analysis of Variability in Road Traffic Accidents in Lagos State, Nigeria. Journal of African Geographical Review. Vol. 28, Pp. 11-41.

[6] Atubi, A. O. (2010c) Road Traffic Accident Variations in Lagos State, Nigeria: A Synopsis of Variance Spectra. Journal of African Research Review. Vol. 4, No. 2, Pp. 197-218.

[7] Auditor Generals Department, Ghana. Performance Audit of the Auditor General on Road Safety in Ghana;

[8] Astrom, J. S., Kert, M. P. \& Jovin, R. D. (2006). Signatures of Four Generations of Road Safety Planning in Nairobi City, Kenya, Journal of Eastern African Research and Development 120:186-201.

[9] Bener, A. and El-Sayyad, G. M. 91985) Epidemiology of Motor Vehicle Accidents in Jeddeh. Journal of the Royal Society of Health, 105:200-201.

[10] Bishai, D., Quresh, A., James, P. and Ghaffar, A. (2006) National Road Casualties and Economic Development. Health Economics, 15, 65-81.

[11] Bjerre, J., Kirkebjerg, P. G. and Larsen, L. B. (2006) Prevention of Traffic Deaths Involving Motor Vehicles. Ugeskrift for Loeger, 168, 1764-1768.

[12] Boateng, P. K. The Chronicle Article, (Thursday May 12, 2011), Curbing Road Accidents in Ghana.

[13] Centers for Disease Control. CDC Surveillance Update. Atlanta: Centers for Disease Control and Prevention; 1988.

[14] Coleman, A. (2014) Road Traffic Accidents in Ghana: A Public Health Concern, and a Call for Action in Ghana, (and the Sub-Region); Open Journal of Preventive Medicine, 2014, 4, 822-828.

[15] Dessie T \& I. arson CP (1991). The occurrence arid driver characteristics associated with motor vehicle injuries in Addis Ababa, Ethiopia. Journal of Tropical Medicine and Hygiene 94, 335-400. 
[16] Feachem, R. G. A; Kjellstorm, T,; Murray, C. J. L.; Over, M. and Philips, M. A. (1992) The Health of Adults in the Developing World, London: Oxford University Press.

[17] Gründl, M. (2005). Fehler und Fehlverhalten als Ursache von Verkehrsunfällen und Konsequenzen für das Unfallvermeidungspotential und die Gestaltung von Fahrassistenzsystemen. PhD Thesis, University of Regensburg, Regensburg.

[18] Hacker, W. (2005). Allgemeine Arbeitspsychologie (2 ${ }^{\mathrm{ND}}$ Ed.). Bern: Hans Huber.

[19] Hazen, A. and Ehiri, J. E. (2006) Road Traffic Injuries: Hidden Epidemic in Less Developed Countries. Journal of the National Medical Association, 98, 73-82.

[20] Holder Y, Peden M, Krug E, Lund J, Gururaj G, Kobusingye O (2001). Injury surveillance guidelines. Geneva: World Health Organization; 2001.

[21] Ismail, A. and Yahia, H. A. H. (2013) Causes and Effects of Road Traffic Accidents in Tripoli - Libya; Proceeding the 6th Civil Engineering Conference in Asia Region: Embracing the Future through Sustainability ISBN 978-602-8605-08-3.

[22] Jacobs G, Aaron-Thomas A, Astrop A. Estimating global road fatalities. TRL Report 445. London: Transport Research Laboratory; 2000.

[23] Ministry of Transport, (2008); Report on Public Transportation, Accra. Ghana.

[24] Mock, C., Kobusingye, O., Anh, L. V., Afukaar, F. and Arreola-Risa, C. (2005) Human Resources for the Control of Road Traffic Injury. Bulletin of the World Health Organisation, 83.

[25] National Road safety Commission Report (2012), Ghana's Response to the Road Safety Challenge.

[26] Obeng, R. M. (2008). Another Look into Road Traffic Accidents, Feature Article. 2008-08-08.

[27] Ofosu, J. B., Abonammoh, A. M. and Bener, A. (1988): A Study of Road Traffic Accidents in Saudi Arabia. Accident Analysis and Prevention, 20:95-111.

[28] Ogunsanya, A. A. (1991) Empirical Cases Studies of Accident and Safety Control of Mass Transit Agencies in Nigeria. In Bolade T, and Ogunsanya A. (eds) Accident Control and Safety measures in Mass Transit Operations in Nigeria. Ibadan: University Press. Pp. 87-115.

[29] Osei-Kyei, R. and Chan, A. P. C. (2016): Developing Transport Infrastructure in Sub-Saharan Africa through Public-Private Partnerships: Policy Practice and Implications, Transport Reviews, 36:2, 170-186, DOI: $10.1080 / 01441647.2015 .1077288$.
[30] Peden, M. (2005) Global Collaboration on Road Traffic Injury Prevention. International Journal of Injury Control and Safety Promotion, 12, 85-91.

[31] Plankermann, K. (2013). Human Factors as Causes for Road Traffic Accidents in the Sultanate of Oman under Consideration of Road Construction Designs.

[32] Reason, J. (2000). Human error: models and management. Journal Digest, 172, 393-396.

[33] Rumar, K. (1999), Speed: A sensitive matter for drivers. VTI Transport Development AB, Nordic Road and Transport Research, No. 1, pp. 20-22.

[34] Smart, R. G. and Mann, R. E. (2002) Death and Injuries from Road Rage: Cases in Canadian Newspapers. Canadian Medical Association Journal, 167, 761-762.

[35] Smith, D. J. (2005). Center for Transportation Research and Education Iowa State University.

[36] Smith, G. S. and Barss, P. (1991) Unintentional Injuries in Developing Countries: The Epidemiology of a neglected problem. Epidemiology Review. 13, 228-266.

[37] World Bank (1990) "Road Safety Problem in the Third World". The Urban Edge. Vol. 14, No. 1.

[38] World Health Organization (1984) Road Traffic Accidents in Developing Countries, Geneva: WHO, TRS 703.

[39] World Health Organization (1989) Analysis of Achievements of Traffic Safety in Industrialized and Developed Countries.

[40] World Health Organization (2014) Global Status Report on Road Safety 2013. WHO Press, Geneva.

[41] World Health Organization (2011) Global Status Report on Road Safety 2010. WHO Press, Geneva.

[42] World Health Organization (2010) Global Status Report on Road Safety 2009. WHO Press, Geneva.

[43] World Health Organization (2009) Global Status Report on Road Safety 2008. WHO Press, Geneva.

[44] WHO and World Bank (2004) World Report on Road Traffic Injury Prevention. WHO, Geneva. Salifu, M. and Mock, C. N. (1998) Pedestrian Injuries in Kumasi: Results of an Epidemiologic Survey. The Ghana Engineer, 18, 2-3.

[45] Wu, S. I. and Malison, M. D. (1990) Motor Vehicle Injuries in Taiwan. Asia Pacific Journal of Public Health, 4:72-75.

[46] Wuaku, D. H. (2016). National Road Safety Commission (NRSC) Report on Road Traffic Accidents Cases in Ghana. 